\title{
LAS RETRIBUCIONES E INDEMNIZACIONES DE LOS MIEMBROS DE LAS CORPORACIONES LOCALES Y EL DERECHO CONSTITUCIONAL A LA INTIMIDAD PERSONAL.
}

\author{
Por Antonio Dominguez Vila
}

Secretario Superior de Admon. Local.

\section{1.-INTRODUCCIÓN:}

El Derecho al honor y a la intimidad personal está garantizado en el artículo 18 de la Constitución y desarrollado por medio de la Ley Orgánica 1/82 de 5 de mayo. En el artículo 7.4 de dicha norma se establece que la revelación de datos privados de una persona, conocidos a través de su actividad profesional u oficial de la persona quien los revela, tiene la consideración de intromisión ilegítima en el ámbito de la protección de la intimidad personal y familiar.

A la vista de dicho artículo es menester delimitar la afección que a dicho derecho fundamental se puede producir por la publicidad que pudiera hacerse de las retribuciones que perciben los miembros de las Corporaciones Locales. Pero, con carácter previo, se debe de discernir si las remuneraciones que perciben los concejales en el ejercicio de su función tienen la condición de datos privados o públicos, así como los límites de su privacidad.

\section{A) Regulación en el ámbito funcionarial.}

Las retribuciones de los funcionarios no tienen carácter público en el sentido de necesaria publicidad de las mismas. Unicamente el concepto retributivo complemento de productividad, está previsto en el artículo 23 de la Ley 30/84 de medidas para la Reforma de la función Pública que sea de conocimiento público por los demás funcionarios del departamento u Organismo interesado así como de los representantes sindicales, lo cual implica "a contrario sensu" que el resto de los conceptos retributivos no tienen por qué ser considerados como públicos en el sentido amplio del término, es decir, de conocimiento general de los mismos por cualquiera que lo requiera para ello o de necesidad de hacer público las cantidades percibidas. Dicho de otra manera, en el ámbito de la función Pública quien pretende acceder al conocimiento de las retribuciones de un funcionario público, salvo la necesaria publicidad que como hemos visto precisa el complemento de productividad, ha de solicitarlo por escrito debiéndose pedir autorización al órgano de la Corporación Competente, en este caso, como mínimo el Alcalde o Presidente que 
ostenta la Jefatura Personal, según el art. 41.14 del ROFRJEL, para acceder por motivos fundados de carácter judicial o administrativo a la nómina o a las retribuciones del funcionario, estimándose inexcusable siempre, el previo trámite de audiencia o con el conocimiento del funcionario para salvaguardar los derechos constitucionales del artículo 18 y del 24.1 ya que ha de ofrecérsele la posibilidad de oponerse y defenderse en un proceso judicial o procedimiento administrativo del que pudiera no tener conocimiento. O en todo caso, ejercitar su derecho a oponerse a tal medida.

\section{B) Las Retribuciones de los miembros de la Corporación.}

Respecto a los emolumentos de los miembros de las Corporaciones Locales, el artículo 13.1 del R.O.F. establece que los miembros electos de las Corporaciones Locales tendrán derecho a percibir de los Presupuestos de dicha entidad, las retribuciones e indemnizaciones que correspondan, dividiendo la percepción de las mismas en:

a) Los miembros de la Corporación que ejerzan dedicación exclusiva que exija la dedicación preferente al cargo, en el caso en que dichas ocupaciones deban ser remuneradas con perioricidad. Exigiendo la ley que sea el Pleno Corporativo el que determine, dentro de la consignación global contenida a tal fin en los presupuestos,qué cargos de la Corporación han de desempeñarse en dedicación exclusiva y las cuantias que correspondan a cada uno de ellos en atención a su grado de responsabilidad, de lo que hay que colegir que serán públicas, en la medida en que lo es el Presupuesto de la Corporación, las retribuciones asignadas a los cargos que ostentan miembros de las Corporaciones Locales con dedicación exclusiva. Esta publicidad tiene una causa de tipo político, pudiéndose suscitar debate sobre las mismas, así como emplearse como argumento por parte de otros miembros de la Corporación en el ejercicio de la oposición y control del gobierno de la Corporación y su Alcalde o Presidente, con su correlativo reflejo en los medios de comunicación, entendiendo que no se incurre en violación del derecho a la intimidad personal por ello, aunque se debe exigir la ponderación debida en la publicidad de estos datos en virtud del artículo 16.3 del R.O.F.R.F.J.E.L, que exige a los miembros de las Corporaciones Locales, guardar reserva en relación con las informaciones que se les faciliten.

b) En segundo lugar sólo existe el derecho a recibir indemnizaciones por los gastos ocasionados en el ejercicio de su cargo, previa la justificación documental, según las normas de aplicación general para las Administraciones Públicas y según normas generales que apruebe el Pleno Corporativo, para aquellos concejales que no tengan la dedicación exclusiva. 
c) Por último, los miembros de la Corporación que tampoco tengan dedicación exclusiva, sólo podrán percibir indemnizaciones en la cuantía general que en el Pleno se determine por su asistencia efectiva a las sesiones de órganos colegiados de los que formen parte.

En ninguno de estos dos últimos casos, se establece una necesaria publicidad de estas retribuciones, ni de las periódicas ni de las indemnizaciones, aunque como hemos visto, las periódicas han de figurar en los Presupuestos, pudiendo ser objeto del debate político y por ende aparecer en los medios de comunicación, sin que ello signifique violación del derecho a la intimidad personal.

\section{C) Derecho al acceso a la información administrativa.}

Respecto al acceso a la información que obra en los documentos administrativos, el artículo 14 del R.O.F.R.J.E.L. establece que los miembros de la Corporación tienen derecho a obtener cuantos antecedentes obren en poder de los servicios de la Corporación, con arreglo a una serie de normas que se desarrollan en los articulos 15 y 16 del mismo texto normativo, pero ha de hacerse notar que se refiere única y exclusivamente a los miembros de la Corporación, siendo este precepto desarrollo del artículo 77 de la Ley de Bases de Régimen Local. En la legislación autonómica de desarrollo en materia de régimen local, cabe destacar, una vez más, el silencio de la Ley Territorial Canaria 8/86, que remite en su artículo 76 a la Ley de Bases de Régimen Local, dejando otro tema más en la ambigüedad, de las muchas que la imperfección técnica de su título IV contiene.

Más explícita es la Ley de 15 de abril de 1987, no 8/87, de desarrollo del régimen Local para Cataluña, que en su artículo 149.1 y 2 limita el derecho de los miembros de las Corporaciones Locales a obtener, del Alcalde o Comisión de Gobierno, los antecedentes, datos o informaciones, que sean necesarios para el desarrollo de su función, a la previa solicitud por el miembro de la Corporación interesado, debiéndose denegar cuando el conocimiento o difusión de la información pueda vulnerar el derecho constitucional al honor, la intimidad familiar o la propia imagen.

Por otro lado, el artículo $230 \mathrm{del}$ mismo R.O.F.R.J.E.L., establece la regulación del derecho a la información general ciudadana, es decir, información que respecto a las cuestiones municipales precise obtener cualquier ciudadano que no sea miembro de la corporación, se refiere a copias o certificaciones acreditativas de acuerdos municipales o antecedentes de los mismos, así como las consulta de archivos y registros que se podrá realizar, previa la solicitud por escrito en la Oficina de Información Municipal y autorización de la autoridad municipal competente, al Alcalde. También este extremo se encuentra desarrollado 
en el artículo 140 de la Ley Catalana, con el procedimiento de obtención de la autorización, superando en claridad y pormenorización al R.O.F.R.J.E.L. Ha de observarse, que tanto la ley autonómica como el derecho estatal supletorio se refieren a "acuerdos municipales" ya tomados, debiéndose exigir por coherencia, justificar en la solicitud, el interés legítimo o afección que dicho acuerdo le produce al instante.

\section{Conclusiones:}

Por lo anterior, se ha de concluir que la obtención de datos, relaciones con copias de los emolumentos que perciben los miembros de las Corporaciones Locales, tanto si son percibidos en concepto de retribución periódica por su dedicación exclusiva a las tareas de gestión de la Corporación, como si son indemnizaciones puntuales por asistencia a las sesiones de los Organos o por gastos ocasionales en el ejercicio de su cargo de concejal o Consejero, no podrán ser hechos públicos, con carácter general, aunque sí puestos en conocimiento de los restantes miembros de la Corporación. Existiendo una sutil diferencia entre las retribuciones periódicas de los cargos que conllevan la dedicación exclusiva que al estar especificadas en los Presupuestos, son de conocimiento público a su través y las indemnizaciones puntuales cuya cuantía, es lo que se debate con ocasión de los presupuestos, pero el monto que corresponde a cada miembro de la Corporación, en cada período de devengo, no debe tener más publicidad que aquella que el Presidente de la Corporación pueda darle, por motivos de la aplicación de lo previsto en el art. 78.4 de la Ley de Bases y 18 del ROFRJEL, con imposición de sanciones y retirada de asignaciones por faltas injustificadas a las sesiones de los órganos municipales. Cualquier solicitud de conocimiento que se pretenda obtener por persona o entidad que no sean miembros de la Corporación, deberá de solicitarse por escrito y resolverse por el Presidente de la Corporación, entendiendo que salvo que sea en vía judicial donde el afectado ya se encuentre procesado, en los demás casos, habrá de ponerse expresamente en conocimiento del miembro de la Corporación afectado. 